\title{
Evaluating Legal Status of Inconsistent Possessions with Stipulation
}

\author{
Arefe Emadi Baladehi ${ }^{1} \&$ Javad Niknejad $^{2}$ \\ ${ }^{1}$ Department of Law, Ayatollah Amoli branch, Islamic Azad University, Amol, Iran \\ ${ }^{2}$ Department of Law, Qaemshahr branch, Islamic Azad University, Qaemshahr, Iran \\ Correspondence: Javad Niknejad, Department of Law, Qaemshahr branch, Islamic Azad University, Qaemshahr, \\ Iran. E-mail: j.n406@yahoo.com
}

Received: January 21, 2017

Accepted: January 28, 2017 Online Published: February 21, 2017

doi:10.5539/res.v9n1p271

URL: http://doi.org/10.5539/res.v9n1p271

\begin{abstract}
In our law, in both terms of analysis and legal principles, condition is not a part of consideration so commitment due to the condition cannot be known at the same level of main conventional commitments, but condition has a relative independence while it has dependence and communication with contract. In fact the condition is an independent undertaking which its survival has been depended to existence of contract by backbone of both parties not vice versa. The final purpose of both parties from obligation and undertaking is realization of contingent commitment; so a condition which its execution to be out of responsibility of one against whom the condition is made is null such as each non-executive commitment. Invalidity of impossible condition cannot be known lack of intention of both parties. Therefore the invalidity of impossible condition can be known abort of tradition and necessity of Gharar in the condition. The purpose of conducting this was evolution of legal status of inconsistent possession with stipulation and is bail of executing opposing transaction inconsistent with condition different according to this issue that legal inconsistent possession to be covenented or possessory contract.
\end{abstract}

Keywords: stipulation, legal arrogation, corporeal arrogation, obligation of both parties

\section{Introduction}

Condition in the word has been mentioned in the meaning of obligation and undertaking to something and in term condition has been used in several meanings. Its term meaning is direct and indirect commitment related to contingent contract. Conditions are divided into three categories of description, act and result. Condition of description is that a certain description is conditioned in one of considerations; condition of act is that doing or not doing an act to be conditioned on one of contracting parties or on both of them or on the third party, condition of result is that result of a legal act to be conditioned in stipulation of a contract including contract or unilateral contract. Stipulation subject is considered as one of important legal juridical subjects which complex problems are expressed in it, one of these problems is: sometimes occurs that one of contracting parties transfers something to another due to condition of result and then without permission of one against whom a condition is made, makes another transaction with another person about that thing.

This situation may occur about condition of act, so that one of contracting parties becomes responsible to act or inaction due to a condition of act and then to do a legal act inconsistent with it. For example, a person in the format of condition of act becomes commitment to sell his automobile to opposite part but then he endows it or sells it to another person.

About such legal possessions which are conflicting with condition of act or result, there is this subject that, are mentioned possessions null or correct or valid or invalid? There are two major theories about this issue in religious jurisprudence and law: some of jurisprudents and lawyers believe that the conflicting transaction is correct, because chose in possession is created for transferee of conflicting transaction but one against whom a condition is made has the chose in action and in confliction between chose in possession and action, chose in possession is prior to the chose in action; so secondary legal possession is correct. Some others of jurisprudents and lawyers believe that conflicting transaction with condition is invalid because according to this theory in Iran's law there is no difference between chose in possession and action but all rights are respectful, and a right which has been created sooner than another is prior to another right. Therefore conflicting transaction with condition is invalid according to this viewpoint. So purpose of conducting present research is evaluation of legal status of inconsistent possession with stipulation. 


\section{Adverse Condition with Law}

After evaluating different viewpoints of jurisprudents about validity of this category of conditions, it seems that most of jurisprudents according to libertarianism of possessions of human in his property, have considered the obligation tradition to lack of possessions from types of obligation to abandon rights belonging to no particular person. Obligation to abandon rights belonging to no particular person is against to book and Sunnah according to the presented rule by jurisprudents, unless subject of the condition to be applicable abandonment of that right or its absolute abandonment in a period of time.

It has been concluded from this rule: obligation lack of possessions absolutely is null and against the book and Sunnah, it is same for obligation to a certain lack of possession such as not-selling. Therefore the mentioned condition has been known correct only in the case that it becomes bailiff to the most partial applicability such as obligation to not-selling it to a sertain person or obligation to lack of possession in a certain time, so that condition of not-selling or donation and... is not allowable according to famous statement of jurisprudents (Mohaghegh Damad, 2006, p. 172).

Disagreements of jurisprudents about validity or defects of obligation applicability to abandon right is due to difference of beliefs about partial being or generality of a condition that its content is abandonment of right, so that some know impunible the obligation of buyer to not sell object of sale from applicabilities of commitment to abandon partial action that its result is validity of the condition. But some others know such obligation general, unless the obligation to not-selling to be conditioned to a certain person. By deeper look at the issue in dispute, it can be said that: separation should be considered between two cases of conditions.

Sometimes according to the condition it is possible that the person become obligant to not have any right to sell his properties. This condition without doubt is one of obligation applicabilities to abandon right generally, because the proprietor has become responsible for such commitment to all his properties. But sometimes the person according to sale stipulation and in the place of buyer becomes obligant to not sell the object of sale to others or not mortgage.

In this assumption, the buyer has been obliged to not selling or not mortgage a certain property (sales). This issue represents the being slight of obligation to leaving permissible. Belief to the permissible condition to leave permissible should be overseer to the slightest is without any reason (Katouziyan, 1999, p. 237).

Secondly, the application of the rule predominant الناس مسلطون على امو الهم).

That the civil law has also referred it in Article 30 is in cases of doubt. According to this rule the principle is that in all forms possessions is allowed for the owner, unless its opposite is proven in accordance with religious arguments. So whenever be doubted to owner capture license. According to this rule, we say: due to the lack of religious reason on prohibiting, the owner is allowed to possession, so cannot be known mandatory religious rule the provisions of the rule. However, in a way that Abuse and condition so that its infringement to be not permissible and to know its opposite condition contrary to scripture and tradition is contrary to Scripture and tradition.

As the owner the exercise of the right to own property as owner can sell or rent it or lose it order to apply their property rights, can be committed by his will that specific material or legal possessions do or not to do in the sales. It should be noted that such a requirement would be minor. Buyer's obligation for has no possession both material and legal forever in sales requires a denial of ownership (Ghanavati, 2012, p. 421).

It should be noted that non absolute condition of possession, contrary to the requirements of the nature of the contract of sale that is also referred to that in the future. In fact, in this case, there is no serious intention to between contract and condition because of the contradiction between contract and condition and condition, so there is no condition to speak on its legitimacy. After theoretical analysis, in general, about the credit of condition of negative legal act from the legal perspective can be said: commitment to lake of possessions is considered as law if it bet in general.

Cannot be justified commitment to no purchasing any property or selling any property, because of these commitments, by considering the totality of its subject, can know a kind of limitation of freedom in civil matters or commitment on lack of using the freedom against the law and public order. Article 960 of the Civil Code is documentary of this idea. Jurists also have known the obligation to lack of possessions generally as examples of solvent and void confident provisions also owner's commitment to the lack of applying any possession both material and legal is in his property indefinitely.

Because the obligation to such a condition requires the negation of all the works of ownership, Legislator has known permissible and allowed any material and legal possession of owner in their property. Owner obligation to lake of applying none of possessions is general obligation and against the law. Of course, if such obligation 
takes place on sales during the contract of sale, reason of invalidity of the condition, is its opposition to the requirements of nature of the contract of sale, which is owned contract. In this case there is no condition due to a conflict between contract and condition to be raised the issue of its legitimacy (Allameh, 2000, p. 422). Commitment to non-possession is not against the law as minor. Legislator in Article 30 of the Civil Code provides any possession has given to owner if it is not against the law. Obligation of owner to lake of possessions as minor is the best examples of the owner authorities. As an owner can sell their property or gift, or give mortgages owned or nullify to their property, can be obligation to lake of specific possessions or lake of possessions in certain period of time. Such obligation, due to it takes place compared to certain property, is minor. In assuming obligation to lake of possessions as absolute insert a specified period, makes minor such a condition (Allameh, 2000, p. 422). In addition, as noted, the provisions of Article 30 of the Civil Code (Rule of innominate) applies in cases of doubt, in this way that it is axiomatic that owner can make any possession in its own property, unless the law has excepted it. So if we have doubts as to whether the buyer can be obligated in this case, the innominate principle requires that to know correct such obligation, it is not to warrant for corruption, also by virtue of the principle of validity of condition can be decreed the accuracy of such conditions.

\section{Compensation for Losses Arising from Violating the Condition}

As the lake of mirror of sales or violation of correct condition will be led to option, lack and corruption of condition in assuming the stipulation ignorance for loss will also option. Because being corrupt of condition is similar to be placed the correct condition under the violation. In other words, for stipulation arise right to terminate if conditioner not do correct condition. Right to terminate arises when condition to be during the corrupt and vicious; Because in both cases the person who the condition takes place in his favor does not reach to his right and therefore to the same reason that option of terminate is made of correct condition, three reasons has been existed to made option to terminate in case of corruption. To prove the option of terminate in case of violating of condition or avoiding faithful to it. In we evaluate the proposed reasons.

A-The first reason that jurisprudents have stated to prove the right to terminate in opton of violation of condition is the consensus of jurists and since the in fact the consensus is a lip reason that should be confined to itself. Therefore, it cannot be extended to other cases like the corrupted condition (Zeraat, 2002, p. 310).

B-The second reason that jurists have stated for the proving the right to terminate in the case of option of condition violation evidence inflicted in rejecting loss or no loss rule. The non-fulfillment of obligations arising from the proper condition or Violation of Correct condition or Violation of obligation condition of stipulation to carry out the provisions of (contract) without condition will lead to prejudicing the stipulation and compensate for this loss granting the right to terminate the stipulation is necessary (Ansari, 1996, p. 289). In fact, when one stipulation is satisfied to the contract with condition. Although this condition is supplementary and subordinate aspects in building consent and violation of its or non-fulfillment to it will not lead to nullity of contract. But the adherence of stipulation to contract without conditions will be caused to prejudicing him. So inevitably to compensate for damages to the stipulation must be considered a measure, however, predict option of contract terminate provides the possibility of losses for him. But is it possible to fundamentals for proves the right to terminate for the corrupt condition or not. Some believe that this rule cannot prove the right to terminate the corrupted condition; Because reasons negate the loss inflicted any case is not a group of jurists cannot create the religious order but only does negate loss order not to create a new religious order (Mousavi, 2012, p. 200; Naraqi, 1471, p. 55). And because in issue of corrupt condition is not seen the effect of promise to proving the option in words of companions so promise to lake of realize option of terminate has been known strong (Ansari, 1996, p. 289). As well as the rule of no loss, do not negative a loss that affected person ignorance is not due to his fault, but is due to his failure because the one who has mistaken and does not go looking for science, is entitled to bear the loss. But the group believe that this rule can prove its right to terminate of the corrupted condition; Because they believe that no loss rule as being include loss provisions also include the provisions of privation loss, in other words, no loss rule also negated the order and prove order. And this rule is not limited to meet the order provisions and can be easily inferred that the situation warrants. Therefore, here, and many others on the basis of the same principle can be created order option. As a result, can be said that it is correct to say the no loss rule also includes the existence affaires also and non-existence affaires and not only meeting order has loss but also proving order has also loss because how can be believed that the scope of the doctrine of denial of loss is limited to the elimination of laws and acts of existence of loss. As may be falsified legal have losses for self or community, the silence and lack of ignorance, in turn, may also have losses. For example, any mismanagement in legal and political relations arising from government performance is whether a country is a result of poor regulation or due to lack of proper regulation and doing provision (Makarem, 1413, p. 87). So with can be sustained evidence of rejection loss (rule no harm) as a basis for fixing option condition was caused by 
corruption; because it eliminates the condition of the consent of the parties in terms of corruption and adherence to the terms of the stipulation of contract No Evil (i), it is caused losses and to compensate for this loss, granting the right to terminate the stipulation is necessary.

C-The third and most important reason that has been expressed to prove option of ignorance of correct condition is avoid of incurring unwanted treaty and the respecting provisions consent. Whenever the parties to conclude a contract and, while it also contained a provision, by mutual consent of the parties has been belonged to a contract However, in this consent building has subordinate aspect, ignoring condition does not cause the nullity of contract. But the stipulation satisfaction to terms of the contract would not be complete without conditions; Because provisions of the reasons mentioned is obligation to fulfill contract provisions (Abedian, 1993, p. 392). In other words, if a contract is signed without condition, the provisions of the contract are obligation to contract of subject. But if a contract be signed with a condition the provisions of the contract are not absolutely obligation the content of the contract. If this condition is impossible, since the content of the contractual obligation is subject to the act and fulfill the requirement. There is no obligation to fulfill the contract for the stipulation is, however, evidence of the necessity to fulfill the contract and will not be included because of the need and therefore has the right to terminate the stipulation (Tabatabaei, 1999, p. 138; Mousavi, 1491, p. 94; Naraqi, 1471, pp. 65-66). Thus, as in abuse condition, stipulation is bound by the provisions of the contract, subject to the fulfillment of the conditions set by mutual consent of the parties and if the corruption bet out there for her commitment and adherence to the terms of the contract, the stipulation is so choice offered in the transaction will be terminated (Tabatabaei, 1999, p. 138; Mousavi, 1491, p. 193). Article 232 and 233 indicating the condition did not consent; Because if you do not know that if the provisions of the corrupted condition of consent (main contract) spread, the contract is void because if indicating consent know in each case must cause corruption condition of nullity of marriage we do not know the condition indicating consent. Also attributed the cucumbers to comply with the terms of consent. This means that at the time of signing the consent is implicit that if corruption or violation of the requirements for abstention have the right to terminate. But this analysis cannot be the norm rather than civil law (with the option of separating the concept of breach of condition) (consistory, 1378, p. 202). So cannot be consent provisions as a basis for termination in case of corruption provided proof of option. We reply that it is a violation of Hrangyzh and Dai person cannot be considered cause for terminating cucumbers, crisp and clear. But the condition, even though the motivation and drive is assumed to be open to the parties of contract can be signed the contract territory and obligations of the parties in the contract it was included in the row is not personal motives. Also, due to the commitment of the marriage relationship bets and bets on the first set of obligations original purpose and not parties. Therefore, we cannot eliminate corruption and conditions attached to the invalidity of contract because they generally eliminate the consent of the parties (Zeraat, 2002, p. 325). In fact, the obligation arising from the condition in step consequential and incidental purpose and the motivation of the parties to the contract and may be effective in the exchange rate. So if you remove the condition regarding violations or excuse condition can be satisfied with the stipulation that marriage is not perfect. In short, the stipulation to be bound by the terms of the contract, subject to fulfillment of condition and if excuse implicit condition for the stipulation left and right to terminate the contract will come for him naturally.

\section{Discussion and Conclusion}

Purpose of conducting the present research was evaluation of legal status of inconsistent possessions with stipulation, according to the conducted evaluations it can be concluded that:

1) Condition is called equivocal; because it has several conditional and term meanings. Purpose of the condition (the intended meaning in this thesis), in legal term is an agreement to be mentioned stipulation of another contract based on certain nature of the subject of that or mutual consent of both parties and become its function.

2) In our law, in both terms of analysis and legal principles, condition is not a part of consideration, so commitment due to the condition cannot be known at the same level of main conventional commitments, but condition has a relative independence while it has dependence and communication with contract. In fact the condition is an independent undertaking which its survival has been depended to existence of contract by backbone of both parties not vice versa.

3) The final purpose of both parties from obligation and undertaking is realization of contingent commitment; so a condition which its execution to be out of responsibility of one against whom the condition is made is null such as each non-executive commitment. Invalidity of impossible condition cannot be known lack of intention of both parties. Therefore the invalidity of impossible condition can be known abort of tradition and necessity of Gharar in the condition. 
4) Some reasons have been said to express invalidity of useless condition such as: abort useless condition, dissuasion of necessity reasons of loyalty to condition from useless condition, lack of right sequence on one against whom a condition is made to lapse of property. In fact the most important and general reason that can be expressed for invalidity of useless condition is abort of condition.

5) That illegal condition which has been recognized from void conditions in explanation of the third paragraph of Article 232 of the Civil Code will include "unlawful condition", "unconstitutional condition" and "contrary to public order and good morals condition".

6) In viewpoint of Shia jurisprudents, illegal condition has been discussed under topics of: "Condition against scripture and tradition 'and' the condition of unlawful solvent and solvent unlawful". Purpose of condition against scripture and tradition is that the person not becomes obligate to a matter which is against with what is consonant and certain. There is no doubt in invalidity of condition against scripture and tradition although some statements have been quoted to prove this claim and Jurisprudents have claimed to have consensus about invalidity of condition against scripture and tradition.

7) Purpose of "unlawful condition" which is one of applicability of illegal condition is condition against the inevitable change violation of the law (jus cogens rules); so only opposition of condition with one of legal factors existing in legal system is not enough for invalidity of its action.

8) One of applicability of illegal condition is contrary to public order and good morals condition. Concept of "good moral" has relationship with "public moral" of the society. Moral in each society is formed as the result of inherited beliefs, habits, customs, and especially religious education and it creates set of rules which are known binding within themselves. Violation of these moral rules leads to hurting public morality and conscience of the society and for this reason such rules cannot be violated and are not reversible through private contracts and conditions.

9) Each contract as soon as realization has some effects and needs some matters these matters are called circumstances. These effects are not same in terms of importance. Some of them have been linked to nature of the contract so that the contract is not concluded without that effects and contact loses its nature. These effects are called absolute parts of contract or the nature circumstances of contract. Some others are only in order to complete contract condition and follow common backbone of both parties. These effects are called absolute parts of contract or the nature circumstances of contract.

10) Invalidity of condition against the requirement of contract nature can be known: illegitimacy, consensus, conflict between creative intention signifier and signified condition contract and conflict between the provisions of the contract and condition. The most important and general invalidity of invalidity of condition against the requirement of contract nature can be known internal conflict of contract set and condition.

11) Validity of condition against the requirement of contract predication can be expressed in this way: when stipulation become against requirement of contract predication, in fact it doesn't fight with requirement of contract, but real struggle is in a constraint that wants to destroy predication in the form of condition and because basically predication has been created in order to obey constraint, in this struggle constraint will be winner. Predication of constraint is removed with constraint's winning and nature of that contract is not removed but a part of that becomes deprived and another part becomes available and the absolute nature of the contract has found existence with available sort.

12) Unclear condition is one of applicability of void conditions. If ignorance to condition has permeated to main contract and leads to unclearness of one of both considerations of contract since awareness to the transaction and considerations is one of basic conditions of validity of transactions, so the contract will become void in terms of nullifying one of conditions of its validity and its stipulation will become decadent because of lack of subject.

13) Condition according to set of mutual consent of parties and quality of relationship of contract and condition in set of mutual consent, the first and main purpose is not parties. So its nullifying doesn't lead to desirable nullifying and mutual consent of contracting parties and consequently there is no reason for perverseness of contract due to perverseness of condition.

14) Although in structure of mutual consent, condition has subsidiary and consequential role and it is not first and main purpose of contracting parties but because common backbone of parties of the contents has linked condition to contract and made a unique combination from that, so that if we want to know one against whom a condition is made who has consented contract with decadent condition obligate to contract without condition, in fact we have made him obligate to an unwanted contract which has disadvantage for him. This undesirable has become reason 
to give the right to terminate to the unconscious damaged (ignorant) in order to prevent and compensate incurred loss or prevent forcing unwanted contract.

15) Effect of void conditions in the contract can be expressed in this way:

A) If impossible condition doesn't make intrigue in basic principles or condition of validity of transaction, the impossible condition will be void but doesn't void the contract and leads to counterfeit authority in the benefit of one against whom a condition is made.

B) Useless condition is never intruder of contract bases, so we accept validity of contract beside the useless condition.

C) If illegal condition to be independent of main commitment (conventional) and doesn't make the subject or direction of main contract illegal, certainly it has no effect on validity of the contract.

D) Condition against requirement of contract nature due to conflict between content of condition and contract make condition invalidity and nullifies the contract. Of course if both parties of the matter don't want any other lawful, because sometimes it can deal with announcements of both parties well that both parties have wanted another lawful action requirement.

E) Unclear condition, when its ignorance spreads to considerations or leads to ignorance of one of the both not only it is decadent but also its imply contract is voided too and this is due to this matter that in fact an element of elements has vitiated contracts and stops realization of contract.

16) Our law is clear about waiving correct conditions. As waiving correct condition is by one against whom a condition is made and he can ignore his right, waiving the void condition is allowable too. Although separation should be considered between the decadent condition that corrupts contract and decadent condition that doesn't corrupt contract.

17) According to general rule of subjacency of condition from contract we know that a condition that the both parties inserted in main stipulation will be voided and decadent by perverseness and cancellation of main contract, although difference should be considered between the assumption that has been not executed and the mode that the condition has been executed.

18) Legal inconsistent possessions of stipulation are possessions that are based on those conditions that are inserted in stipulation of sale contract and whereby transaction party in legal (including positive and negative) faces some limitations. Nature of this type of conditions such as other conditions is dependency and keeping in the contract (in product meaning) and obligation of one against whom a condition is made. So that as soon as obligation of one against whom a condition is made, conditional contract is concluded absolutely and it is necessary for one against whom a condition is made to practice the contents of the condition.

19) Nature of mentioned conditions depends on type and way of its insertion in stipulation. If the mentioned conditions to be inserted in stipulation as condition of act, content of the condition: is only commitment of buyer to apply or not apply some possessions, but it doesn't reduce dominium of one against whom a condition is made, so that according to the condition, chose in the action is created for seller. Chose in action is a right that person has to another person and according to that can ask him to do something for him.

Owner of the chose in action is called creditor and buyer who has been obliged to do the condition is called debated or debtor. The original of right is in validity of owner of that claim and in terms of obligate it is commitment or debt which its issue is restraint to some of legal possessions, it should be said that in an assumption that buyer is obligated to apply or not apply some special possessions, influence and validity of such condition is personal and limited to contractual relationship of both parties, so that only emptor who is creditor can want obligation of buyer to content of the condition.

Such obligation is relative and according to the nature of chose in action doesn't have citation capability against all and it is executable only for debate. Also chose in action doesn't imply right of persecution and its issue only can be asked from buyer.

20) Sovereignty of humans' backbone requires that transacting parties to be able to make each condition that they want in the contract. Restrictive conditions of buyer ownership are in the category of this type of conditions and in line with accepting principle of sovereignty of humans' backbone. Insertion of restrictive conditions of buyer ownership is allowable in the case that to be not against requirement of essence of sale contract and doesn't hurt the validity of institution of property and also to be not opposite of the law.

21) According to the definition that was presented from requirement of essence of sale contract, requirement of essence of sale contract is the main and basic effect that has been resulted from the contract directly and without 
intermediary and has existed in all people and applicability of that contract and has accompaniment with contract so that is inseparable of the contract and its elimination leads to loss of nature of the contract.

Therefore only tradition of lack of proprietorship of object of sale and price are in category of conditions against requirement of essence of sale contract, also it is in same way for obligation of buyer to not apply any possession including financial and legal. Because in this case although the proprietorship has been not negated directly but it has negation of all effects of accompaniment proprietorship with negation of proprietorship which forms essence of sale contract. Apart from the two above-mentioned other restrictive conditions of buyer ownership are not in the category of conditions against requirement of the contract.

22) Restrictive conditions of buyer ownership are not against the law. Although according to the law, owner can make any possession in his property and absolute legal power of the Owner to Exercise Control Over property in Article 30 of the Civil Code, this matter is emphasized. But it cannot be said that each condition that against contents of this article limits ownership of the buyer is against law and void. As the owner can sell his property in line with applying ownership right or destroy and release it, he can be obligated to apply or not apply some of possessions in object of sale.

In fact such obligation is in line with applying ownership right of the owner and shows full dominance of owner over his property. In addition to this, according to this issue that such obligation is formed to essence of specified (object of sale), it is one of partial applicability of obligation to action or abandonment of the permissible action and it is in legal category (right in particular meaning) which is able to waiving and transfer not to be in the category of judgments. So such obligation is allowable. Principle of validity of contracts and conditions, also principle of sovereignty of humans' backbone and necessity of firmness of contracts and absolute legal power of the owner to exercise control over property in Article 30 of the Civil Code requires to be considered this type of conditions correct and valid.

23) Guaranty of executing breach of condition depends on the way of its insertion. If the aforesaid condition to be inserted in the contract as condition of act, because contents of condition is just commitment of buyer to apply or not apply some of possessions including financial and legal and doesn't reduce ownership right of the buyer. By insertion of the mentioned condition, chose in action is created for one against whom a condition is made that according that he can want obligation of one against whom a condition is made to do the condition from the court.

But according to special feature of chose in action and attention to this issue that ownership of restricted buyer to consistent possessions with condition has been not defected, if buyer conducts legal inconsistent possession with the condition, the mentioned possession is valid and one against whom a condition is made can't request invalidation of legal inconsistent possession with condition from court, but he only has right to cancel the main contract based on authority of breach of condition for one against whom a condition is made. Rational way of compensation of one against whom a condition is made in an assumption that it is not possible for coercion of him, identifying rescission right is for one against whom a condition is made. By cancelation of the main contract by one against whom a condition is made, legal inconsistent possession of the condition is cancelled too.

But if the mentioned condition to be inserted in stipulation as the result, according to this issue that based on the condition of the result, contracting parties are obligated to result of one of contracts or in stipulation and with realization of conditional contract, the intended result is resulted to ago of tradition and one against whom a condition is made is only obligated to effects and results due to legal action, so assumption of breach of condition is not propounded until a speech to be formed about guaranty of its execution. Therefore legal inconsistent possession with condition is void and null.

\section{References}

Abedian, H. (1993). Bets void and its impact on the contract. Tehran: Phoenix.

Allameh, M. (2000). The terms of the contract null and its impact (2nd ed.). Money Press.

Ansari, M. (1996). Makasib (2nd ed.). Tabriz: Press information.

Consistory, N. (1999). Out-of-contract requirements (2nd ed., Vol. 2). Tehran: Tehran University.

Ghanavati, J. (2012). Contract Law (2nd ed., Vol. 1). University Research Institute.

Makarem, S. N. (2002). The rules Alfqhyh (2nd ed., Vol. 1). Qom: Press Mrss·h Ismailis.

Mohaghegh, D. M. (2006). The rules of civil law. Tehran.

Mousavi, B. H. (2012). Alfqhyh jurisprudential-rule. Najaf: Press Aladab.

Naraqi, A. (2006). Ayam Revenues. Qom: Islamic Propagation Office. 
Zeraat, A. (2001). Self-Makasib (Vol. 4). Forest Publishing.

\section{Copyrights}

Copyright for this article is retained by the author(s), with first publication rights granted to the journal.

This is an open-access article distributed under the terms and conditions of the Creative Commons Attribution license (http://creativecommons.org/licenses/by/4.0/). 